\title{
Pyridyl Cyanoguanidine CHS 828
}

National Cancer Institute

\section{Source}

National Cancer Institute. Pyridyl Cyanoguanidine CHS 828. NCI Thesaurus. Code C1852.

A pyridyl cyanoguanidine that exhibits antitumor activity by an unknown mechanism.

$(\mathrm{NCl})$ 